\title{
PERSEPSI MINORITAS MUSLIM TERHADAP MODEL KERUKUNAN DALAM MEMBANGUN HARMONI SOSIAL ${ }^{1}$
}

\author{
Sulanam \\ Universitas Islam Negeri (UIN) Sunan Ampel Surabaya \\ Email: sulanam@uinsby.ac.id
}

\begin{abstract}
Abstrak: "Tulisan ini bertujuan untuk menggambarkan bangunan kerukunan beragama di Kupang, Nusa Tenggara Timur (NTT). Propinsi ini telah berhasil menjadi contoh bagi model dan jalinan kerukunan beragama bagi provinsi-provinsi lain di Indonesia. Sebagai provinsi yang mayotitas Kristen, cara minoritas Muslim dalam mendorong tumbuhnya harmoni, toleransi, ataupun kerukunan juga berbeda dengan di wilayah yang mayoritas muslim. Minoritas ini memiliki kekhasan dalam menterjemahkan bangunan kerukunan beragama di wilayah NTT. Untuk menjawab tujuan penulisan ini, akan digambarkan bagaimana persepsi minoritas muslim NTT dalam membangun model kerukunan beragama; selanjutnya juga akan digambarkan bagaimana pemahaman mayoritas dan minoritas dalam mendorong praktik kerukunan beragama dalam kerangka kebangsaan. Dalam tulisan ini ditemukan bahwa harmoni umat beragama merupakan keniscayaan yang harus terus dibangun demi keutuhan bangsa Indonesia: ada kesadaran bahwa harmoni berbangsa dan bernegara di Indonesia merupakan model ideal yang saat ini menjadi contoh bagi masyarakat dunia. Model-model kerukunan yang dipersepsi minoritas dapat dirawat dan selanjutnya menjadi platform dalam mewujudkan harmoni sosial."
\end{abstract}

Kata kunci: Toleransi, kerukunan beragama, minoritas muslim.

"Waktu saya melamar istri saya, yang ditanya calon mertua, 'kamu NU apa Muhammadiyah?'. Saya kaget sekali, karena kebiasaan di Sini, orang kalau tanya soal itu, biasanya 'kamu Muslim apa Kristen?'.,2

\footnotetext{
${ }^{1}$ Versi awal artikel ini adalah makalah yang disiapkan sebagai bahan presentasi kelas matakuliah Pemikiran Islam Kontemporer dalam Perspektif Global, Program Doktoral Kajian Islam UIN Sunan Ampel Surabaya, 10 Oktober 2017. Penulis mengucapkan terimakasih kepada Dr. H. Imam Mawardi, MA atas berbagai masukan terhadap tulisan ini.

${ }^{2}$ Statemen diatas diperoleh setelah tiga hari bersama dengan seorang pegawai Kantor Wilayah Kementerian Agama, Provinsi Nusa Tenggara Timur (NTT). Ia seorang muslim yang berasal dari Flores - NTT, mempersunting seorang wanita asal Gresik - Jawa Timur, Alumni IAIN Sunan Ampel Surabaya. Betapa berbeda dialog diatas, manakala itu terjadi di Jawa yang notabene mayoritas muslim. Di NTT, mayoritas penduduknya memeluk agama Kristen, dan hanya $10 \%$ yang beragama Islam. Wawancara dengan Mahyan, Kupang, 13 September 2017.
} 


\section{Pendahuluan}

Kutipan diatas memberikan gambaran, betapa cara pandang dalam masyarakat mayoritas berbeda dengan apa yang dialami oleh masyarakat minoritas. Jawa, sebagaimana disebutkan dalam footnote no. 2 adalah wilayah yang dihuni oleh mayoritas muslim, sehingga ranah perdebatan jauh lebih tajam dari sekedar hanya mempersoalkan agama. Perdebatannya menjadi mendalam karena sudah menyangkut faham keagamaan (baca: NU, - Muhammadiyah). Hal tersebut berbeda dengan yang dialami oleh kelompok minoritas. Pernyataan bahwa "Kamu Muslim apa Kristen?", dalam kutipan diatas, sesungguhnya mengindikasikan bahwa di kelompok minoritas mempersoalkan faham dalam suatu agama tidaklah menjadi hal penting.

Hidup sebagai minoritas tentu bukan perkara yang mudah dijalani. Minoritas umumnya kalah (atau mengalah) oleh kuasa mayoritas. Saat mayoritas semena-mena, minoritas dengan segera akan terkikis dan teraniaya. Karenanya, peristiwa-peristiwa tragis yang mengandung unsur kekerasan banyak terjadi pada konflik minoritas-mayoritas. Pada 6 Februari 2011, minoritas Ahmadiyah diserang oleh seribuan warga Cikeusik. ${ }^{3}$ Hal yang sama juga dialami oleh warga Syiah Sampang. Konflik Syiah Sampang yang sejatinya telah bersemai semenjak tahun 2004 dan meletus tajam pada 26 Agustus 2012, ${ }^{4}$ merupakan konflik yang melibatkan hubungan antara minoritas-mayoritas. Di dunia internasional, awal September (1/9/2017) terdapat kasus yang menyita banyak perhatian masyarakat dunia, umumnya bagi mereka yang beragama Islam. Peristiwa itu adalah peristiwa pembantaian etnis Rohingya ${ }^{5}$ di Myanmar.

Ketiga peristiwa itu merupakan peristiwa yang melibatkan konflik minoritas-mayoritas. Bedanya peristiwa Ahmadiyah dan Syiah berlatar faham keagamaan Islam, dan peristiwa etnis Rohingya berlatar etnis "antar agama". Sejatinya hubungan minoritas dan mayoritas juga tidak melulu persoalan agama, karena konflik minoritas dan mayoritas juga ada yang bermotif kecemburuan sosial maupun ekonomi.

Untuk dapat melihat bagaimana pentingnya membangun hubungan yang baik antara minoritas dan mayoritas, tiga kasus kekerasan diatas yang terjadi akibat kurang harmonisnya hubungan antara mayoritas dan minoritas, selanjutnya dapat dijadikan dasar dalam membangun dan pentingnya mengedepankan kerukunan bagi antar umat beragama.

Dalam konteks Indonesia, konflik horizontal yang melibatkan kuasa mayoritas terhadap minoritas sangatlah mudah disulut. Keragaman suku, agama, dan budaya merupakan sebuah keniscayaan konflik manakala antar entitas tidak mampu saling menahan diri dan membangun sikap toleran. Dapat dikatakan, mayoritas provinsi di Indonesia dihuni oleh mayoritas Muslim, hanya beberapa provinsi yang didiami oleh mayoritas non-muslim, seperti provinsi Nusa Tenggara Timur. Situasi yang tidak seimbang ini sejatinya dapat memicu

\footnotetext{
${ }^{3}$ Lihat, Kompas Cyber Media, "Dua Mobil Dan Satu Rumah Dirusak Warga," KOMPAS.com, accessed October 5, 2017, http://regional.kompas.com/read/2011/02/06/14020724/Dua.Mobil.\%1fdan.Satu.\%1fRumah.\%1fDirusak\%1f.\%1fWar\%1fga.

${ }^{4}$ Lihat, "Bagaimana Kronologi Syiah Masuk Sampang? - Nasional Tempo.co," accessed October 5, 2017, https://nasional.tempo.co/read/426989/bagaimana-kronologi-syiah-masuk-sampang.

${ }^{5}$ Lebih lengkap mengenai kasus pembantaian etnis Rohingya lihat "Korban 130 Orang, Muslim Rohingya Dibantai Besar-Besaran," SINDOnews.com, accessed October 5, 2017, https://international.sindonews.com/read/1235782/40/korban-130-orang-muslim-rohingya-dibantai-besar-besaran-1504228502.; "Kecam Pembantaian Etnis Rohingya, Ini Saran Untuk Pemerintah Indonesia,” Jurnas.com, accessed October 5, 2017, http://www.jurnas.com/artikel/21145/Kecam-Pembantaian-Etnis-Rohingya-Ini-Saran-untuk-Pemerintah-Indonesia/.; PT VIVA MEDIA BARU- VIVA.co.id, "Sepekan Di Rakhine, Pembantaian Etnis Rohingya Bukan Hoaks - VIVA.co.id," last modified September 13, 2017, accessed October 5, 2017, http://www.viva.co.id/berita/nasional/956340-sepekan-di-rakhine-pembantaian-etnis-rohingya-bukan-hoaks.
} 
munculnya beragam konflik. Hasilnya, bangunan hidup berbangsa dan bernegara semakin tidak kukuh. Oleh karena itu, mayoritas hendaknya dapat memberikan jaminan terhadap minoritas, dan minoritas juga janganlah terlalu menonjolkan jatidirnya sehingga tidak memunculkan respon yang berlebihan. Mayoritas akan berharga, bermanfaat, dan bermartabat manakala ia mampu melindungi dan menjamin hak-hak minoritas. ${ }^{6}$

Tulisan ini bertujuan untuk menggambarkan bagaimana persepsi minoritas muslim NTT dalam membangun model kerukunan beragama. Selanjutnya juga akan digambarkan bagaimana pemahaman mayoritas dan minoritas dalam mendorong praktik kerukunan beragama dalam kerangka kebangsaan. Dalam kajian ini terdapat dua istilah kunci yang saling berkaitan, yaitu kerukunan dan minoritas. Kajian mengenai kerukunan umumnya ditujukan pada kelompok masyarakat yang timpang: tidak berkoloni secara berimbang; mayoritas berpotensi menindas dan minoritas berpotensi tertindas. ${ }^{7}$ Sedangkan kajian mengenai minoritas umumnya dilihat pada bagaimana cara minoritas bertahan diri atau mengekspresikan jati dirinya. ${ }^{8}$ Ahmad Suaedy menggambarkan bahwa konflik minoritasmayoritas pada dasarnya juga memiliki akar yang kuat pada level identitas kultural, ${ }^{9}$ sehingga apapun jenis konflik yang ditampilkan di permukaan, seyogyanya juga menyentuh ke ranah identitas kultural. Dalam fakta sosial, minoritas umumnya dibicarakan atau diberitakan manakala telah berhubungan dengan sejumlah penindasan atau kekerasan. ${ }^{10}$

\section{Model Kerukunan dalam Persepsi Minoritas Muslim}

Dari segi konsep, minoritas muslim perlu didudukkan secara jernih, apakah ia merujuk pada jumlah kuantitatif atau hanya pada atribut-atribut tertentu yang melekat pada mereka, dan menjadikan mereka dianggap berbeda dari penduduk mayoritas. ${ }^{11}$ Melihat fakta jumlah pemeluk agama Islam di NTT dapat dikatakan bahwa minoritas yang dimaksud di sini adalah berkaitan dengan jumlah (kuantitas). ${ }^{12}$

Sebagai minoritas, muslim di NTT melihat bahwa beragama harus betul-betul memperhatikan aspek harmoni sosial. Beberapa tokoh muslim turut mendorong terwujudnya harmoni sosial, bukan saja didorong oleh ajaran Islam semata, lebih dari itu juga didorong oleh keinginan untuk memberikan jaminan kepada ummat Islam yang ada di NTT agar berada dalam situasi rukun dan damai.

\footnotetext{
${ }^{6}$ Pernyataan Frans Lebu Raya, Gubernur Nusa Tenggara Timur, dalam Audiensi Tim UIN Sunan Ampel Surabaya di Kantor Gubernur Kupang, NTT. 11 September 2017.

${ }^{7}$ Sebagai contoh lihat Ahmad Suaedy, Dinamika Minoritas Muslim Mencari Jalan Damai (Jakarta: Puslitbang Lektur dan Khazanah Keagamaan Badan Litbang dan Diklat Kementerian Agama RI dan CISEAS-The Wahid Institute, 2012).

${ }^{8}$ Kajian mengenai identitas (jati diri) bagi minoritas cukuplah banyak dilakukan. Salah satu cara termudah bagi minoritas dalam mengekspresikan kehidupannya adalah dengan meneguhkan jati dirinya melalui berbagai macam ekspresi, seperti gaya berpakaian, cara berperilaku, cara berbicara, ataupun cara melakukan ritual tertentu. Beberapa kajian mengenai minoritas dan identitas dapat dilihat Hilman Latief, "Islamic Charities and Dakwah Movements in a Muslim Minority Island: The Experience of Niasan Muslims," Journal of Indonesian Islam 6, no. 2 (December 1, 2012): 221-244.; Syamsul Rijal, "Friday Prayer and an Indonesian Islamic Identity in Canberra, Australia," Journal of Indonesian Islam 3, no. 1 (June 1, 2009): 148-167.

${ }^{9}$ Suaedy, Dinamika Minoritas Muslim Mencari Jalan Damai, 3.

${ }^{10}$ Pemberitaan media massa akan menampilkan minoritas, jika kelompok ini dalam situasi yang timpang dan mengalami kekerasan, seperti kasus Rohingya Myanmar, Syiah Sampang, dan Ahmadiyah Cikeusik. Lihat berita Media, "Dua Mobil Dan Satu Rumah Dirusak Warga.”; “Kecam Pembantaian Etnis Rohingya, Ini Saran Untuk Pemerintah Indonesia."

${ }^{11}$ Rina Rehayati, "Munoritas Muslim; Belajar Dari Kasus Minoritas Muslim Di Filipina," Jurnal Ushuluddin XVII, no. 2 (2011): 226.

${ }^{12}$ Lihat footnote no. 2.
} 
Secara harafiah ada perbedaan antara hidup rukun dengan hidup damai. Rukun dapat diartikan sebagai kebersamaan yang mendalam, seperti senang bersama, susah bersama, bermain bersama, bekerja bersama. Singkat kata rukun merupakan cerminan sebuah perkawanan atau persahabatan. Sedangkan damai adalah kebersamaan formal, kebersamaan yang diikat oleh aturan yang dibuat bersama, saling menghargai, tenggang rasa. Singkat kata, damai merupakan cerminan sebuah perkooperasian, perkumpulan, atau pengelompokan. ${ }^{13}$

Melihat kegigihan para tokoh Islam ini, tidak dapat dipungkiri bahwa bangunan harmoni sosial telah diupayakan dapat berjalan dengan baik. Bagi Syamsul Maarif ${ }^{14}$, setidaknya bangunan kerukunan ummat beragama dapat dilihat dari empat macam model, kerukunan generik, kerukunan retorik, kerukunan eksotik, dan kerukunan genetik. ${ }^{15}$ Keempat model kerukunan ini ia gali dari berbagai pengalaman selama menjalani kehidupan sebagai minoritas Muslim di NTT.

\section{Kerukunan Generik}

Kerukunan generik merupakan model kerukunan yang didorong oleh pihak pemerintah melalui serangkaian seremonial, peraturan-peraturan kerukunan umat beragama, serta peraturan-peraturan yang diproduksi oleh pemerintah dalam menjamin kebebasan beragama. Model kerukunan generik, mau tidak mau harus ditaati oleh setiap pemeluk beragama dan batas wilayah terirotial tertentu.

Ikatan yang dibangun dalam kerukunan generik ini selanjutnya dipedomani bersama baik oleh pemerintah provinsi, pemerintah kabupaten, Kantor Wilayah Kementerian Agama, MUI, maupun oleh FKUB. Perangkat-perangkat pelaksana regulasi yang dicetuskan oleh pemerintah tersebut dilaksanakan dan dipakai untuk menjamin kehidupan beragama bagi masyarakat, tanpa tekanan. Pendek kata kerukunan generik adalah model kerukunan yang dimotori oleh pemerintah dan menjamin agar masyarakat dapat menjalankan kehidupan beragama secara nyaman.

NTT sebagai salah satu provinsi di Indonesia juga mengikuti peraturan-peraturan yang telah ditetapkan oleh pemerintah pusat dalam hal kerukunan ummat beragama. Payung hukum yang mendasari kerukunan ummat beragama adalah Peraturan Bersama Menteri Agama dan Menteri Dalam Negeri nomor 9 Tahun 2006 dan nomor 8 tahun 2006 tentang Pedoman Pelaksanaan Tugas Kepala Daerah/Wakil Kepala Daerah dalam Pemeliharaan Kerukunan Umat Beragama, Pemberdayaan Forum Kerukunan Umat Beragama, dan Pendirian Rumah Ibadat. ${ }^{16}$ Peraturan ini menjadi faktor yang mendorong model kerukunan generik.

Kerukunan dapat dicapai melalui proses legislasi, penyusunan sebuah kesepakatan bersama yang kemudian dituangkan dalam aturan-aturan yang mengikat pada kedua belah pihak, atau beberapa pihak. Karenanya, aturan-aturan ini juga butuh disosialisasikan kepada masyarakat. Masyarakat perlu didorong agar memahami berbagai macam legislasi yang mengatur kehidupan rukun mereka.

\footnotetext{
${ }^{13}$ Pusat Kerukunan Umat Beragama, Kementerian Agama RI, "Pemantapan Kerukunan Umat Beragama Dalam Mencegah Berkembangnya Faham Radikalisme” (Jakarta, n.d.).

${ }^{14}$ Kepala Bidang Haji dan Bimas Islam, Kanwil Kementerian Agama NTT.

${ }^{15}$ Wawancara dengan Syamsul Maarif, 12 September 2017 di Rumah Dinas Asrama Haji Kupang.

16 Kementerian Agama dan kementerian Dalam Negeri, Peraturan Bersama Menteri Agama Dan Menteri Dalam Negeri Nomor 9 Tahun 2006 Dan Nomor 8 Tahun 2006 Tentang Pedoman Pelaksanaan Tugas Kepala Daerah/Wakil Kepala Daerah Dalam Pemeliharaan Kerukunan Umat Beragama, Pemberdayaan Forum Kerukunan Umat Beragama, Dan Pendirian Rumah Ibadat, n.d.
} 


\section{Kerukunan Retorik}

Senada dengan kerukunan generik, kerukunan retorik adalah pengejawantahan dari kerukunan generik. Kerukunan retorik merupakan proses penterjemahan terhadap berbagai regulasi ke dalam kehidupan praksis beragama masyarakat.

Model kerukunan ini melihat fakta regulasi dan membandingkannya dengan fakta kehidupan beragama masyarakat, lalu mendudukkan keduanya dalam suatu diskusi, forumforum rembug, seminar, maupun pertemuan ilmiah lainnya, yang bertujuan untuk mencari titik temu, mencari solusi, atau mencari terobosan yang lebih maju dalam berkehidupan beragama masyarakat.

Model kerukunan retorik, lebih menitikberatkan pada proses dialog, diskusi, seminar, ataupun lokakarya yang berhubungan dengan kehidupan beragama dan kerukunan ummat beragama. Model kerukunan ini lebih maju dari model kerukunan generik, yang hanya berfokus pada penerbitan regulasi.

Meski model ini lebih maju, Maarif tampaknya tidak menolak jika dalam model kerukunan retorik, juga dapat dikatakan sebagai "beda tampak muka, akan beda pula tampak belakang". Maksudnya, setiap individu dan tokoh-tokoh yang sedang menyampaikan pentingnya kerukunan dan bangunan kehidupan yang harmonis tentu juga memiliki agenda terselubung (hidden agenda). ${ }^{17} \mathrm{Hal}$ ini dikatakan wajar, mengingat setiap manusia, apalagi mereka yang sudah berada pada posisi tertentu sebagai tokoh panutan masyarakat, tentu tidak bisa serta merta melihat sesuatu sebagaimana adanya. Melihat sesuatu justru akan ia lihat bersamaan dengan apa yang ada dibalik sesuatu yang sedang terjadi tersebut.

Beberapa contoh model kerukunan yang dapat dikategorikan sebagai kerukunan retorik, sebagaiamana tampak dalam presentasi Gubernur NTT pada kuliah umum di UIN Sunan Ampel Surabaya. Kegiatan inovatif untuk mewujudkan harmoni dan toleransi antar umat beragama di NTT dicapai melalui (1) pengembangan ekonomi umat melalui kelembagaan agama, (2) memfasilitasi pimpinan kelembagaan ke tempat-tempat suci keagamaan, (3) penyelenggaraan hari raya keagamaan bersama, (4) menjadikan Aula Rumah Jabatan Gubernur sebagai tempat penyelengaraan perayaan hari besar keagamaan, dan (5) dialog keagamaan antara Gubernur dengan Pimpinan Lembaga Keagamaan, Tokoh-tokoh Agama, Tokoh-tokoh Pemuda Lintas Agama ${ }^{18}$

Jika melihat platform Gubernur NTT diatas, salah satu cara terpenting dalam membangun kerukunan antar umat beragama adalah dengan dialog. Dialong ini menjadi bagian penting atas berbagai problem keummatan, utamanya yang berkaiatan antar/intern pemeluk agama (keyakinan). Dengan dialog segala hal yang berkaitan dengan prasangka, persepsi, atau kecurigaan dapat diminimalisir. Dialog-dialog, yang meski tampak permukaan bisa jadi berbeda dengan kedalaman niat seseorang, dapat dijadikan sebagai sesuatu yang mengikat kedua belah pihak.

Gambar di bawah menunjukkan bahwa pembinaan kerukunan perlu dicapai melalui proses legislasi (model kerukunan generik) dan proses dialog (model kerukunan retorik).

\footnotetext{
${ }^{17}$ Ibid.

18 Frans Lebu Raya, "Kebijakan Inovatif Membangun Harmoni Umat Beragama Dan Penguatan Jatidiri Kebangsaan Di Provinsi Nusa Tenggara Timur" (Power Point presented at the Kuliah Umum, Surabaya, October 6, 2017).
} 
Keduanya perlu dilakukan secara ajeg, dengan cara sosialisasi, fasilitasi, dan capacity building. ${ }^{19}$

\section{Gambar 1: Pembinaan Kerukunan}

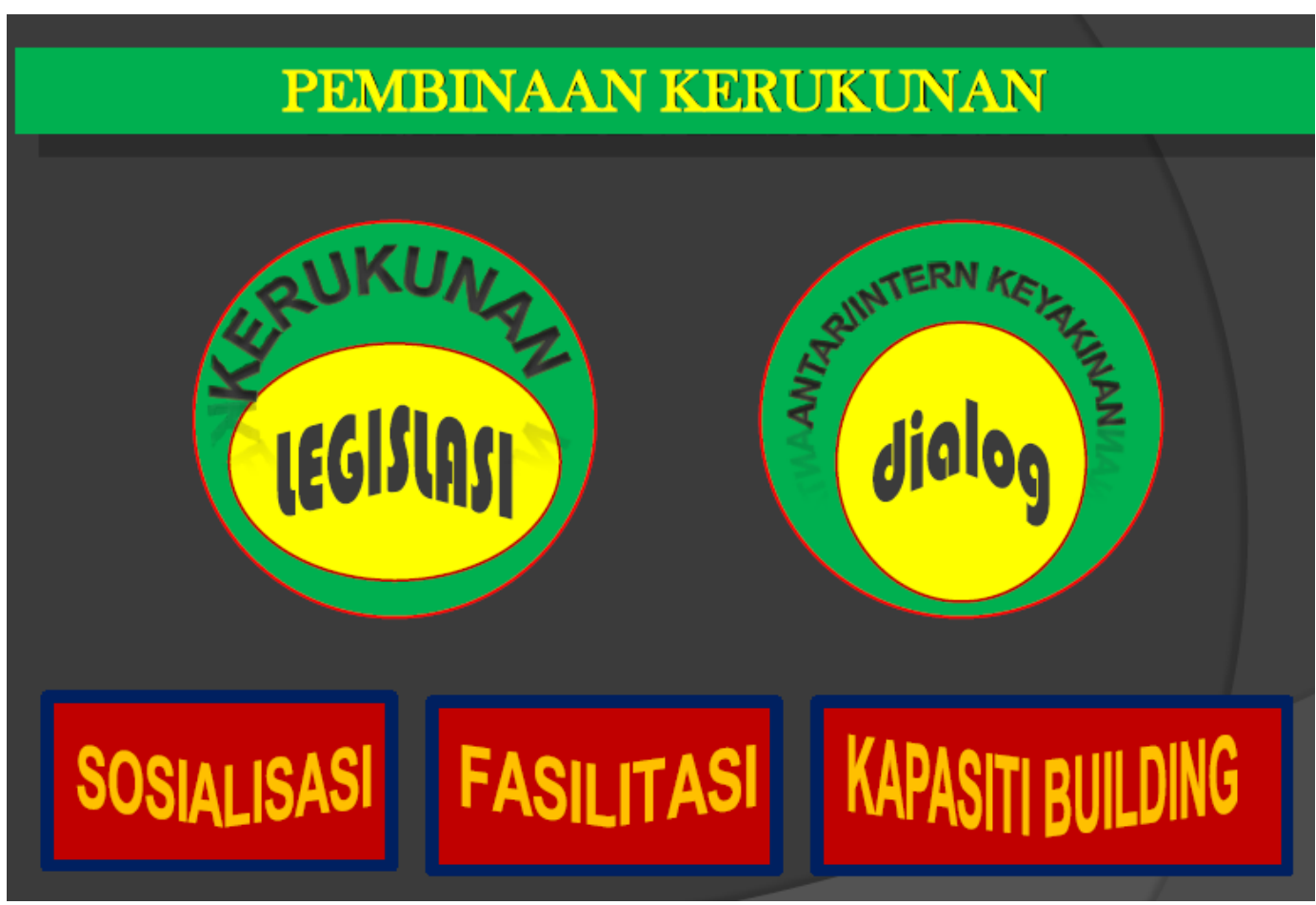

\section{Kerukunan Eksotik}

Berbeda dengan dua model kerukunan diatas, kerukunan eksotik lebih menitikberatkan pada bangunan kerukunan yang simbolik dan praktik-praktik yang memiliki nuansa hidup rukun: saling membantu dan saling berbagi. Bagi Maarif ${ }^{20}$, kerukunan simbolik seperti yang telah dipraktikkan oleh seorang Ibu Kepala Kantor Kementerian Agama di Kabupaten Ende, NTT yang sering memakai jilbab/hijab saat menghadiri kegiatan-kegiatan ummat Islam. Ia mengisahkan, saat melakukan upacara pemberangkatan jamaah haji, kepala Kemenag ini juga tak segan memakai jilbab. Semata-mata ia lakukan untuk menghargai ummat Islam yang sudah terbiasa memakai jilbab. Contoh lain yang ia sampaikan adalah seorang Frater ${ }^{21}$ yang memberikan pengajaran di sebuah pesantren, juga kegiatan bersama antara Suster dan santriwati.

Secara simbolik, dapat dikatakan bahwa model kerukunan yang dipraktikkan oleh kepala Kemenag ini adalah suatu keindahan: betapa jalinan Muslim-Kristen juga bisa ditampilkan secara apik, satu sama lain saling menghargai dan menghormati. Model yang demikian inilah yang seharusnya dijaga, bukan malah dicibir atau dihujat. ${ }^{22}$

Mungkin di daerah lain, kisah indah ini tidaklah indah. Tetapi bagi minoritas, kisah ini betul-betul dapat menjadi indah karena ia telah disentuh sampai ke bagian yang paling mendalam: menggunakan atribut muslim atau membantu orang-orang Islam untuk

\footnotetext{
${ }^{19}$ Pusat Kerukunan Umat Beragama, Kementerian Agama RI, "Pemantapan Kerukunan Umat Beragama Dalam Mencegah Berkembangnya Faham Radikalisme."

${ }^{20}$ Wawancara dengan Syamsul Maarif, 12 September 2017.

${ }^{21}$ Frater: Calon Pastor. Lihat https://kbbi.web.id/frater accessed October 5, 2017.

${ }^{22}$ Wawancara dengan Syamsul Maarif, 12 September 2017.
} 
memperoleh pengetahuan yang lebih maju. Kerukunan eksotik adalah model dialog antara apa yang diyakini dengan aktifitas keseharian yang ditampilkan. Model yang demikian ini berguna bagi minoritas, karena mereka merasa terayomi, ${ }^{23}$ keberadaan mereka telah dilihat sebagai sesuatu yang dihargai, dan identitas minoritas diterima sebagai sebuah keindahan.

\section{Kerukunan Genetik}

Kerukunan genetik merupakan kerukunan yang diwariskan dalam keluarga secara turun temurun. Kerukunan genetik hanya dapat dijumpai pada keluarga yang memiliki agama campuran. Fakta-fakta mengenai kerukunan genetik ini dapat dijumpai secara baik dalam keluarga yang memiliki keyakinan agama berbeda-beda.

Di NTT juga terdapat keluarga dengan latar belakang keyakinan yang berbeda-beda. Praktik-praktik kerukunan biasanya ditampilkan pada saat acara keagamaan masing-masing individu dalam keluarga. Jika ia muslim, maka pada saat lebaran keluarga yang non-muslim akan memberikan penghormatan, begitu juga sebaliknya.

Selain itu, praktik lain adalah munculnya dukungan dari keluarga yang sedang mendirikan rumah ibadah, saat pembangunan musholla di salah satu kampung, hampir keluarga yang non-muslim juga turut bahu membahu dalam pendirian musholla tersebut. Karena, di NTT, perikatan keluarga sangat kuat. Bahkan bisa jadi satu kampung adalah keluarga semuanya. Satu dengan yang lain, tak peduli beda keyakinan, akan dibantu semampunya. $^{24}$

Dari keempat model kerukunan yang dikisahkan oleh Maarif diatas, perlu digarisbawahi bahwa keempat model tersebut selanjutnya dipersepsi dan dipakai untuk mensikapi berbagai macam dinamika antar ummat beragama. Dari persepsi keempat model tersebut selanjutnya digunakan untuk memilah dan melihat permasalahan-permasalahan yang terjadi dalam berbagai kehidupan beragama di wilayah NTT. Tentu harus diakui bahwa selain keempat model ini, persepsi lain juga masih ada dan terbuka.

Untuk melihat bangunan hubungan minoritas mayoritas lainnya di NTT ini, tidak dapat dipisahkan dari melihat bangunan relasi minoritas-mayoritas muslim - Kristen secara nasional. Mafhum kita ketahui bahwa Kristen di Indonesia adalah minoritas, karenanya tidak menutup kemungkinan adanya kajian lebih lanjut untuk melihat apakah hubungan yang dibangun di NTT ini semata dipengaruhi oleh faktor kearifan lokal saja, atau itu semua terjadi, juga atas kesadaran mayoritas NTT bahwa mereka - di sisi lain dalam pentas nasional adalah minoritas.

Terlepas dari itu semua, pesan penting dalam membangun kerukunan adalah samasama saling. Kata saling ini membutuhkan upaya dialog yang setara atau dialog yang tidak mengedepankan ego masing-masing. Baik secara generik maupun secara retorik, bangunan kerukunan mengharuskan adanya sosialisasi, fasilitasi dan capacity building yang baik dan terencana. Baik bagi minoritas dan mayoritas, kerukunan dimaknai sebagai modal sosial bagi pembangunan dan kemajuan suatu daerah. Mustahil tanpa situasi yang stabil, pembangunan dapat terwujud dengan baik.

\footnotetext{
23 Ibid.

${ }^{24}$ Wawancara dengan Mahyan, 12 September 2017.
} 


\section{Simpulan}

Kesadaran minoritas dalam memahami empat model kerukunan umat beragama dapat dikatakan sebagai bentuk peneguhan jati diri mereka, saat berinteraksi sosial dengan kelompok mayoritas. Disamping itu, kesadaran dalam memegang teguh keempat model ini dan upayanya untuk terus mewariskan kesadaran ini telah dapat mendorong pada terciptanya bangunan kerukunan umat beragama di NTT.

Kelompok minoritas yang menyadari bangunan kerukunan sebagai sebuah keniscayaanuntuk mendapatkan rasa aman-dapat dipahami sebagai salah satu cara mereka untuk tetap merawat pola hidup rukun dan damai. Kesadaran minoritas ini sejatinya harus terus dirawat dan disemaikan ke berbagai individu yang ada dalam kelompok minoritas. Kelompok mayoritas yang memiliki kesadaran bahwa "mayoritas akan bermartabat jika dapat mengayomi minoritas" merupakan awal yang baik bagi terpenuhinya jalinan kehidupan yang rukun dan damai.

Baik kelompok minoritas dan mayoritas haruslah sama-sama memiliki bangunan kesadaran bahwa model kerukunan yang telah dipraktikkan di NTT adalah model terbaik yang selanjutnya dapat dijadikan sebagai contoh bagi provinsi-provinsi lain di Indonesia. Hal yang tak kalah penting di NTT ini adalah adanya kesepahaman bersama bahwa menjaga dan merawat kerukunan merupakan model bagi bangunan harmoni kebangsaan, yang selanjutnya menjadi bagian penting dari sebuah contoh berbangsa dan bernegara yang baik. Kesadaran tentang Indonesia sebagai contoh negara dengan mayoritas muslim dan dapat hidup rukun di tengah porak porandanya bangunan berbangsa di kalangan negara-negara Islam di Timur Tengah sejatinya merupakan modal yang kuat bagi persemaian harmoni berbangsa dan bernegara.

\section{Daftar Rujukan}

Kementerian Agama dan kementerian Dalam Negeri. Peraturan Bersama Menteri Agama Dan Menteri Dalam Negeri Nomor 9 Tahun 2006 Dan Nomor 8 Tahun 2006 Tentang Pedoman Pelaksanaan Tugas Kepala Daerah/Wakil Kepala Daerah Dalam Pemeliharaan Kerukunan Umat Beragama, Pemberdayaan Forum Kerukunan Umat Beragama, Dan Pendirian Rumah Ibadat, n.d.

Latief, Hilman. "Islamic Charities and Dakwah Movements in a Muslim Minority Island: The Experience of Niasan Muslims." Journal of Indonesian Islam 6, no. 2 (December 1, 2012): 221-244.

Lebu Raya, Frans. "Kebijakan Inovatif Membangun Harmoni Umat Beragama Dan Penguatan Jatidiri Kebangsaan Di Provinsi Nusa Tenggara Timur.” Power Point presented at the Kuliah Umum, Surabaya, October 6, 2017.

Media, Kompas Cyber. "Dua Mobil Dan Satu Rumah Dirusak Warga." KOMPAS.com. Accessed October 5, 2017. http://regional.kompas.com/read/2011/02/06/14020724/Dua.Mobil.\%1fdan.Satu.\%1fRumah.\%1fDirusak\%1f.\%1fWar\%1fga.

Pusat Kerukunan Umat Beragama, Kementerian Agama RI. "Pemantapan Kerukunan Umat Beragama Dalam Mencegah Berkembangnya Faham Radikalisme,” Jakarta, n.d.

Rijal, Syamsul. "Friday Prayer And An Indonesian Islamic Identity In Canberra, Australia." Journal of Indonesian Islam 3, no. 1 (June 1, 2009): 148-167. 
Suaedy, Ahmad. Dinamika Minoritas Muslim Mencari Jalan Damai. Jakarta: Puslitbang Lektur dan Khazanah Keagamaan Badan Litbang dan Diklat Kementerian Agama RI dan CISEAS-The Wahid Institute, 2012.

VIVA.co.id, PT Viva Media Baru-. "Sepekan Di Rakhine, Pembantaian Etnis Rohingya Bukan Hoaks - VIVA.co.id." Last modified September 13, 2017. Accessed October 5, 2017. http://www.viva.co.id/berita/nasional/956340-sepekan-di-rakhine-pembantaianetnis-rohingya-bukan-hoaks.

"Bagaimana Kronologi Syiah Masuk Sampang? - Nasional Tempo.co.” Accessed October 5, 2017. https://nasional.tempo.co/read/426989/bagaimana-kronologi-syiah-masuksampang.

"Kecam Pembantaian Etnis Rohingya, Ini Saran Untuk Pemerintah Indonesia." Jurnas.com. Accessed October 5, 2017. http://www.jurnas.com/artikel/21145/KecamPembantaian-Etnis-Rohingya-Ini-Saran-untuk-Pemerintah-Indonesia/.

"Korban 130 Orang, Muslim Rohingya Dibantai Besar-Besaran." SINDOnews.com. Accessed October 5, 2017.2 https://international.sindonews.com/read/1235782/40/korban-130-orang-muslim-rohingya-dibantai-besarbesaran-1504228502. 